\title{
Strategic Unification of Artificial Intelligence in Foreign Direct Investment Application Forms
}

\author{
Hansa Edirisinghe ${ }^{1} \&$ Ruvan Abeysekera ${ }^{2}$ \\ ${ }^{1}$ Department of Computer Science, IIC University of Technology, Cambodia \\ ${ }^{2}$ School of Computing, ESOFT Metro Campus, Colombo, Sri Lanka \\ Correspondence: Hansa Edirisinghe, Department of Computer Science, IIC University of Technology, Cambodia. \\ Tel: 94-767-326-888. E-mail: hansa@iic.edu.kh
}

Received: November 25, 2021 Accepted: December 7, 2021 Online Published: December 8, 2021

\begin{abstract}
A foreign direct investment (FDI) is a very popular method of investing overseas but different from a stock investment in a foreign company. It could be purchasing of an interest in a company by an investor located outside its borders and in most cases, governments pay special interest on them. This is a business decision to acquire a substantial stake in a foreign business or to buy it outright as to expand its operations to a new region. Embedding artificial intelligence (AI) across the business requires significant investment and a change in overall approach. It is highly constructive and productive transformation that should be planned professionally, applied systematically, and managed strategically. AI drives meaningful value to business through better decision-making and consumerfacing applications. The general perception about filling a FDI application is a cumbersome job. Some countries manage this stage very methodically and investors always give priority for them as they can commence the production/business activities within a short period. Those countries who fail to gain this competitive advantage tend to lose the FDI opportunities even if they own various other advantages of resources to attract investors. This paper attempts to evaluate the potential of embedding a strategic unification of artificial intelligence in the application forms used to fill by investors at the time of starting foreign direct investment projects.
\end{abstract}

Keywords: foreign direct investment, artificial intelligence, machine learning, neural network, robotics, expert systems, fuzzy logic, natural language processing

\section{Introduction}

Foreign direct investment (FDI) is an integral part of an open and effective international economic system and a major catalyst to development (OECD, 2002). However, FDI in developing countries has a bad reputation. It is sometimes considered as tantamount to postcolonial exploitation of raw materials and cheap labour (Moran, Görg, Seric, \& Krieger-Boden, 2017). IBM defined machine learning as a branch of artificial intelligence (AI) and computer science which focuses on the use of data and algorithms to imitate the way that humans learn, gradually improving its accuracy (IBM, 2020). In a laymen point of view, artificial intelligence is the simulation of human intelligence processes by computer operated systems.

The application process of an overseas business investment is usually cumbersome phenomenon. If a government cannot operate a flowless investment application process the FDI in that country will not prosper. All comparative advantages, advantages due to strategic locations etc. will be useless if the investors are inconvenienced in the application process. This leads to create a bad image about the country and continue to lose of potential investors to the hosting country. Delays in government approvals and licensing have an opportunity cost for international investors responding to concession auctions and solicitations for bids (Saeed \& Lamech , 2003). Therefore, countries those who need foreign direct investments always look for methods to simplify the process and facilitate inflow of foreign exchange to the country. The business areas that traditionally provide the most value to companies tend to be the areas where AI can have the biggest impact (Chui, Henke, \& Miremad, 2018). International trade refers to the exchange of capital, goods, and services across international borders or territories (Edirisinghe L., The Influence of Logistics Competence in International Trade in Sri Lanka: A Contemporary Study, 2017). This paper explores the relevance of artificial intelligence in Investment application processing. The term, "strategic unification" in this paper refers to the process of being united or combined to make a comprehensive outcome to the FDI application using AI. 


\section{Foreign Direct Investment}

FDIs are commonly made in open economies and one of the key influencers is to have skilled workforce and growth prospect. As far as the host country is concerned, FDIs not only bring money with them but also skills, technology and knowledge and expertise is specific fields (business-standard, 2021). The challenges usually faced by the host countries includes establishing a transparent, broader, and effective enabling policy environment for investment and to build the human and institutional capacities to implement them. A risk is an unavoidable element of every financial investment. However, in overseas investments it is usually even riskier as the business environment is more complicated than a domestic investment in its own country (Nwanji, et al., 2020). When a company or an entrepreneur invest money in a foreign country, there are many additional risk components such as constraints for access to different information, hidden costs that are not common in domestic environment, sole dependency on a broker or investment adviser, changes in currency exchange rate, various ad hoc currency controls by authorities etc. (Edirisinghe \& Koggalage, 2021). The risk involvement with foreign exchange or popularly known 'forex' risk is the risk of losing money due to fluctuations in currency exchange rates (Yao \& Tan, 2000). This situation could be critical particularly when the investments are taking place between developed and underdeveloped countries.

\section{FDI Application Form (IAF)}

Foreign investment application form is the initial document an investor submitted to the intended country of investment. The respective government makes all efforts to make this process more user friendly. Due to global competition to attract more investors to facilitate foreign direct investment, particularly in developing countries, consistently review the application process and ease the burden at the initial stage. The Law stipulates the principle of nondiscrimination between domestic and foreign investors in terms of investment applications (UNCTAD, 2003). The common comports of an FDI application were identified and listed in table 1, according to the FDI applications and government circles of Sri Lanka, Pakistan, Bangladesh and Maldives (Board of investment of Sri Lanka, 2021) (Board of Investment of Pakistan, 2021) (Bangladesh Investment Development Authority, 2021) (Invest Maldives, 2021).

Table 1. Comparison of the features of FDI application from between four countries

\begin{tabular}{lcccc}
\hline Key Sections of FDI application form & Sri Lanka & Pakistan & Bangladesh & Maldives \\
\hline Project Type & $\sqrt{ }$ & $\sqrt{ }$ & $\sqrt{ }$ & $\sqrt{ }$ \\
Sector & $\sqrt{ }$ & $\sqrt{ }$ & $\sqrt{ }$ & $\sqrt{ }$ \\
Proposed Fix Capital Investment for one Year & $\sqrt{ }$ & $\sqrt{ }$ & $\sqrt{ }$ & \\
Proposed Working capital Investment for one Year & $\sqrt{ }$ & & $\sqrt{ }$ & $\sqrt{ }$ \\
Source of Finance & $\sqrt{ }$ & & $\sqrt{ }$ & $\sqrt{ }$ \\
Public Utility Service Required & & & $\sqrt{ }$ & \\
Proposed Manpower requirement & $\sqrt{ }$ & $\sqrt{ }$ & $\sqrt{ }$ & $\sqrt{ }$ \\
Estimated time frame & $\sqrt{ }$ & $\sqrt{ }$ & $\sqrt{ }$ & \\
Estimated Production or Services for one year & $\sqrt{ }$ & $\sqrt{ }$ & $\sqrt{ }$ & $\sqrt{ }$ \\
\hline
\end{tabular}

Accordingly, a FDI application generally focusses on the project type and the sector of manufacturing or service. Other key component in a FDI is the capital investment that usually consist, intended cost of land, building, manufacturing plant, and other equipment etc. Proposed working capital of the investment and the proposed source of finance should be indicated to the screening authorities. It could be foreign or local share capital or loan. Depending on the type of business the investor may need variety of public utility services in the investing country. After the project commences the investor needs various types of human resources. The proposed manpower requirement should be indicated to the authorities in advance enabling smooth operation. It may consist expatriates for managerial, supervisory, clerical and technical positions. The staff in the new investment may include both skilled and unskilled workers. This is a very sensitive area for a government because of the country's unemployment and underemployment status. 


\section{Artificial Intelligence (AI)}

According to the dictionary, AI is the development of computers that can be applied to processes like human thinking, such as logic and self-correction. However, it changes over time due to rapid growth of technology. At a certain level of development AI was known as imitating intelligent human. In addition to the general definition of artificial intelligence, there are many profound interpretations as well. However, most of those interpretations could be categorized under system think like human, system act like human, system think rationally and system act rationally (Kok, Boers, Kosters, Putten, \& Poel, 2020). The domain of AI has a broad set of extensive techniques branched based on the AI Capabilities. The six major branches of AI are (i) Machine learning (ML), (ii) Neural Network (NN), (iii) Robotics, (iv) Expert Systems (ES), (v) Fuzzy Logic (FL) and (vi) Natural Language Processing (NLP). Generally, all types of AI deliver consistent results leading to many AI powered visual agents are available in the market today (O'Leary, 2013).

\subsection{Major Branches of AI}

\subsubsection{Machine Learning}

ML is a study of computer algorithms that improves automatically through the expectance. With the application of complex mathematical capabilities, programmers design machine learning algorithms encoded in machine language to create a complete ML system (McQueen, Gamer, Nevill-Manning, \& Witten, 1995). ML enables to execute a task to categorize, decipher and estimate data from a given data set. It is a technology that enables a computer to learn without being programmed, translate, process and analyze data to solve problems in the real world (Guo, et al., 2017). The type of the ML algorithm will be selected based on the types of data available and the preferred output (Aznarte \& Siebert, 2017). The three major categories of ML are supervised learning, unsupervised learning and reinforcement learning (Lingitz, et al., 2018). Supervised learning is a task driven approach which data specialists feed on labeled training data algorithms and define variables for the algorithm to access and find correlations (McCoy \& Auret, 2019) (Zupan, Demsar, Kattan, Beck, \& Bratko, 2000) (Edwards, New, \& Parker, 2012) (Ridwan, et al., 2021).

\subsubsection{Neural Network}

$\mathrm{NN}$ is a process which is very similar to the brain process of a real human. A set of algorithms that are used to find elemental relationships across the bunches of data via a process that imitates the human brain operating process (Hafezi, Shahrabi, \& Hadavandi, 2015). A computer learning system that uses a functional network to understand and translate one type of data input to the desired output, usually in a different way (Guo, et al., 2017) (Yao \& Tan, 2000). The NN can be used as part of various machine learning algorithms to process complex data inputs into a space that computers can understand (Singh, Basant, Malik, \& Jain, 2009) (Campisi-Pinto, Adamowski, \& Oron, 2012).

\subsubsection{Robotics}

Robotics is another important branch of artificial intelligence that focuses on the design and development of robots. Both science and engineering methods contribute to robotics, which involves the design, construction, and operation of robots (Lee, Choi, \& Sohn, 2018).

\subsubsection{Expert Systems}

ES are artificial intelligence systems that are simply designed to study and mimic a person's decision-making ability. It uses logical numbers to solve complex problems and does not use traditional programs (Kwong, Ip, \& Chan, 2002).

\subsubsection{Fuzzy Logic}

FL is a technology that represents and alters uncertain information by measuring the level of hypothesis accuracy. It is also used to argue about concepts that are naturally uncertain. Fuzzy logic makes machine learning methods easier to implement and helps to logically imitate human thinking (Kwong, Ip, \& Chan, 2002).

\subsubsection{Natural Language Processing}

NLP is another important part of AI that enables computer and human communication in natural language. It is a technique of computational processing human languages, enables the computer to read and understand data from the natural language of human communication (Chopra, Prashar, \& Sain, 2013) (Nadkarni, Ohno-Machado, \& Chapman, 2011). 


\section{Research Methodology}

An exploratory study including comprehensive literature survey was done prior to ascertain the methodology of the research. Since the objective of the paper is to identify the appropriateness of artificial intelligence in carrying out the application evaluation for foreign direct investment, the researchers conducted an opinion survey to collect primary data and desk research to substantiate the claims. The research was conducted in Sri Lanka and the target population of this study consisted selected top official in relevant Ministries, senior officers of Board of Investment (BOI), Sri Lanka, Customs, leading manufacturing firms covering both private, and public sectors as well as firms registered under BOI and non-BOI. A qualitative analysis was administered to get the response of structured sections of questionnaires. Non structed sections was compiled based on most relevant areas for the study

Since the paper does not carry any statistical analysis other key research methods have been used as appropriate. Accordingly, the research approach of this paper is three folded. It consists a combination of opinion survey, desk research and a case study. Semi structured questionnaire was designed for the interviews based on the previous research under similar topics. Initially, convenient sample of seven opinion leaders representing stakeholders of the investment sector have been identified. This sample size was chosen as a matter of judgment. However, three more respondents were subsequently contacted based on the comments received at the survey. Due to pandemic situation of Covid 19 majority of meetings were converted to live interactive zoom meetings and telephone conversations. However, efforts have been made to maintain the quality of discussions despite these unavoidable circumstances during the period the study was conducted, and scheduled time frames were maintained. It was also noted that too large sample may hinder to carryout deep and comprehensive, case-oriented analysis that is the raison-d'etre of qualitative scientific investigation. The discussions were interactive, informal, non-time bound, and the data collection process was nonlinear, iterative to capture more insights. Narrative analysis method was used to administer reformulation of ideologies, experiences, cases, stories presented by respondents. However, representation from majority stratum was single thus it was difficult find correlation or present different experiences of each respondent of each case. Therefore, the common methodology of developing coding, identifying themes, patterns and relationships were skipped. In other words, narrative analysis was limited to the revision of primary data and summarizing them into conceptual illustrations. A great deal of transformation of raw data to critical information through the brain processing was done. Data collection was limited to one researcher to avoid subjectivity of the forming/interpreting information from the raw data and the time of data collection was extended significantly to ensure quality of the data collected for the research.

\section{Case Study}

This case study was done about new investment establishment procedure and promotional mechanism in Sri Lanka. Figure 1 depicts the variation of DBS of Sri Lanka for last 14 years. BOI's does the screening of invertor applications, the investment department in consultation with the Legal Department to negotiate agreements that include the provision of fiscal incentives in exchange for performance commitments. addition to this it verifies or approves lists of any duty-free imports. It works with the Monitoring Department to check investor compliance with agreements (UNCTAD, 2004). Sri Lanka welcomes FDI in most sectors. However, there is a "negative list" of sectors where FDI is barred completely or may only take a minority stake in an enterprise (UNCTAD, 2004). Restrictions on FDI are imposed through the Exchange Control Act. In practice, FDI applications are referred for approval by the Controller of Foreign Exchange to the BOI. Under its Act, the BOI has the power to exempt any enterprise from the Exchange Control Act. The BOI is, in effect, the FDI regulator (UNCTAD, 2004).

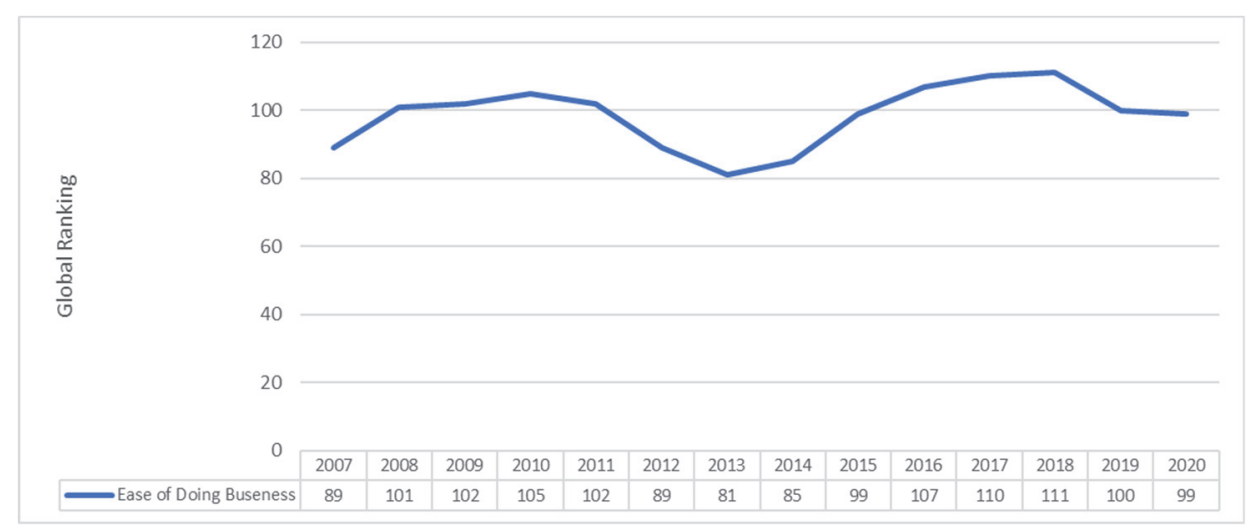

Figure 1. Doing business score (DBS) of Sri Lanka 2007- 2020 
According to Global competitiveness report 2019 under business dynamism pillar Sri Lanka records a very moderate performance despite country's continuous efforts to attract FDIs. Accordingly, administrative requirements Sri Lanka ranks at 72 out of 141 economies in the world. Cost of starting a business (\% of GNI per capita) rank is 79 while time to start a business (days) recorded at 57. New Zealand was adjudged as the best performer in this regard. Regarding the raking of insolvency recovery rate (cents to the dollar) of Sri Lanka in 2019 has been 52 while Japan was the best performer under that category (Schwab, 2019). Foreign direct investment (FDI) into Sri Lanka decreased to \$548 million in 2020, compared to \$793 million in 2019 and \$1.6 billion in 2018 (CCG, 2021). Foreign ownership is allowed in Sri Lanka in most sector However, foreigners are prohibited from owning land with a few limited exceptions. The Cabinet of Ministers should decide the composition of the negative list. Applications by individual foreign investors to co-invest in nationally owned businesses on the negative list should be decided by the BOI. FDI in activities not on the negative list should not require prior approval (UNCTAD, 2004). The application for government approval may not include details on how the merger and acquisition (M\&A) will take place, which is important for making entries in the BOP framework to reflect the transaction (UNCTAD, 2009). It was noted that foreign and domestic investors view the regulatory system are unpredictable with outdated regulations. The best way to change this perception is to improve the application procedure using the modern technology. Using artificial intelligence and machine learning with be the key. the BOI-investor agreements are drafted so as to completely exclude the investor from the application of the Inland Revenue Act during the initial tax holiday period. Most "BOI companies" do not file tax returns in this period (UNCTAD, 2004).

\section{Findings and Discussions}

There are various algorithms, methods and models used to increase the productivity of different industries. The machine learning strategies such as Bayesian Model-Based Clustering, Incremental Conceptual Clustering, Decision tree introduction, Oblique decision tree introduction for numeric data, Conjunctive and disjunctive normal form decision tree, DNF rule generator, Improved prism and First order inductive learner had used to solve problems in agriculture and horticulture. The results were based on the inputs mainly categorized under Environmental descriptors, Conditions of seed, Conditions of fruit pods, Conditions of leaves, Conditions of stem and Conditions of roots (McQueen, Gamer, Nevill-Manning, \& Witten, 1995). The ML algorithms such as Support vector regression (SVR) algorithm, Step-down linear regression model, Gradient boosted regression tree algorithm (GBM), Negative binomial regression model (NBM), Least absolute shrinkage and selection operator (LASSO) linear regression model and Generalized additive model (GAM) were used to develop a model to forecast the dengue spreading in different areas of China (Guo, et al., 2017). Dynamic Line Rating (DLR) using ML is basically the functional change of hypothetical heat capacity for overhead power lines in response to environmental and weather conditions. It has used only the quantity-based components for the forecast since this is a numerical model. Generalized Linear Model, Multivariate Adaptive Regression Spline, Random Forest and Quantile Random Forest were the four ML algorithms which used to get the preferred result (Aznarte \& Siebert, 2017). State-of-the-art regression models in ML used to reduce the lead time with maintain the original quality of semiconductor manufacturing (Lingitz, et al., 2018). ML algorithms such as Linear and nonlinear discriminant analysis (LDA), Decision trees, Classification and regression trees (CART), Random forests (RF), k-nearest neighbors (kNN), Support vector machines (SVMs), Principal component regression (PCR), Partial least squares (PLS) were used to process the data captured by soft sensers in minerals processing (McCoy \& Auret, 2019). Perdition of health risk, prediction of residential electrical consumption and prediction of rainfall are some other areas which were taken advantages of ML (Zupan, Demsar, Kattan, Beck, \& Bratko, 2000) (Edwards, New, \& Parker, 2012) (Ridwan, et al., 2021).

As a major branch in AI Neural network (NN) is another widely used technology for the forecasting. Hafezi, Shahrabi, \& Hadavandi, 2015 has proposed a model to predict the stock price by using Nural Network. It is a multi-agent framework called bat-neural network multi-agent system (BNNMAS) which has four layer multiagent framework to predict eight years of DAX stock price in quarterly periods. Feature selection algorithms (FS), Time lag selection and Bat algorithm (BA) are the NN algorithms used for this model (Hafezi, Shahrabi, \& Hadavandi, 2015). Similarly, Yao \& Tan, 2000 has used NN model to predict the foreign exchange rates. The exchange rates between American Dollar and 5 other major currencies such as Japanese Yen, Deutsch Mark, British Pound, Swiss Franc and Australian Dollar are forecast by the trained neural networks. The NN algorithm named Backpropagation algorithm was used for this model and the traditional rescaled range analysis is used to test the efficiency of each of the market before using historical data to train the neural networks (Yao \& Tan, 2000). Apart from that, $\mathrm{NN}$ was used to forecast the future sales of a printed circuit board factory; forecast the wind speed when generating wind energy; predict daily mean ambient temperatures; and predict the river water quality in 
water purifying (Chang, Liu, \& Fan, 2009) (Guo, Wu, Lu, \& Wang, 2011) (Dombayc1 \& Gölcü, 2009) (Singh, Basant, Malik, \& Jain, 2009).

As per the view of the appraisers who attend the FDI application form in the investment facilitation organization, he/she gives the priority to some specific information. Therefore, making that information in the application form at the primary stage helps to expedite the entire process rather than the evaluation process going back and forth many times. The Business markets prefer rational decisions based on economic discipline than emotional choices usually found in consumer markets (Edirisinghe L. , Strategic Marketing Management in Container Shipping: application of Ten S Model, 2017). There are some information that the investor can provide while various other supporting data are available in the system. Usually, data becomes useful information after a systematic brain process. In other words, having raw data may not add any value to the working process. In this instance that crucial transformation with be undertaken by the AI.

The key objective of the paper is to discuss about strategic inclusiveness of artificial intelligence to improve the application processing of FDIs. In the study the tool considered for evaluation is the application form. Since the investment application is the first formal experience the investor gets from the respective country it should create a strong image to attract the investors. While the investment promotion authority needs more information of the investor, the process should be a convenient and tireless experience to the investor. Accordingly, detailed discussions have been carried out with the respondents to identify the gaps in the current FDI application form. The information that needs to be derived from the historical data has been identified based on the comments by respondents. Then those were segregated to different data categories enabling effective and efficient problemsolving mechanism through AI. Table 2 illustrates the key findings of the literature about AI algorithms, models and methods used to solve similar problems in referred case studies considering the appraiser's point of view.

Table 2. Representation of AI algorithms, models and methods used to solve similar problems in referred case studies considering the appraiser's point of view

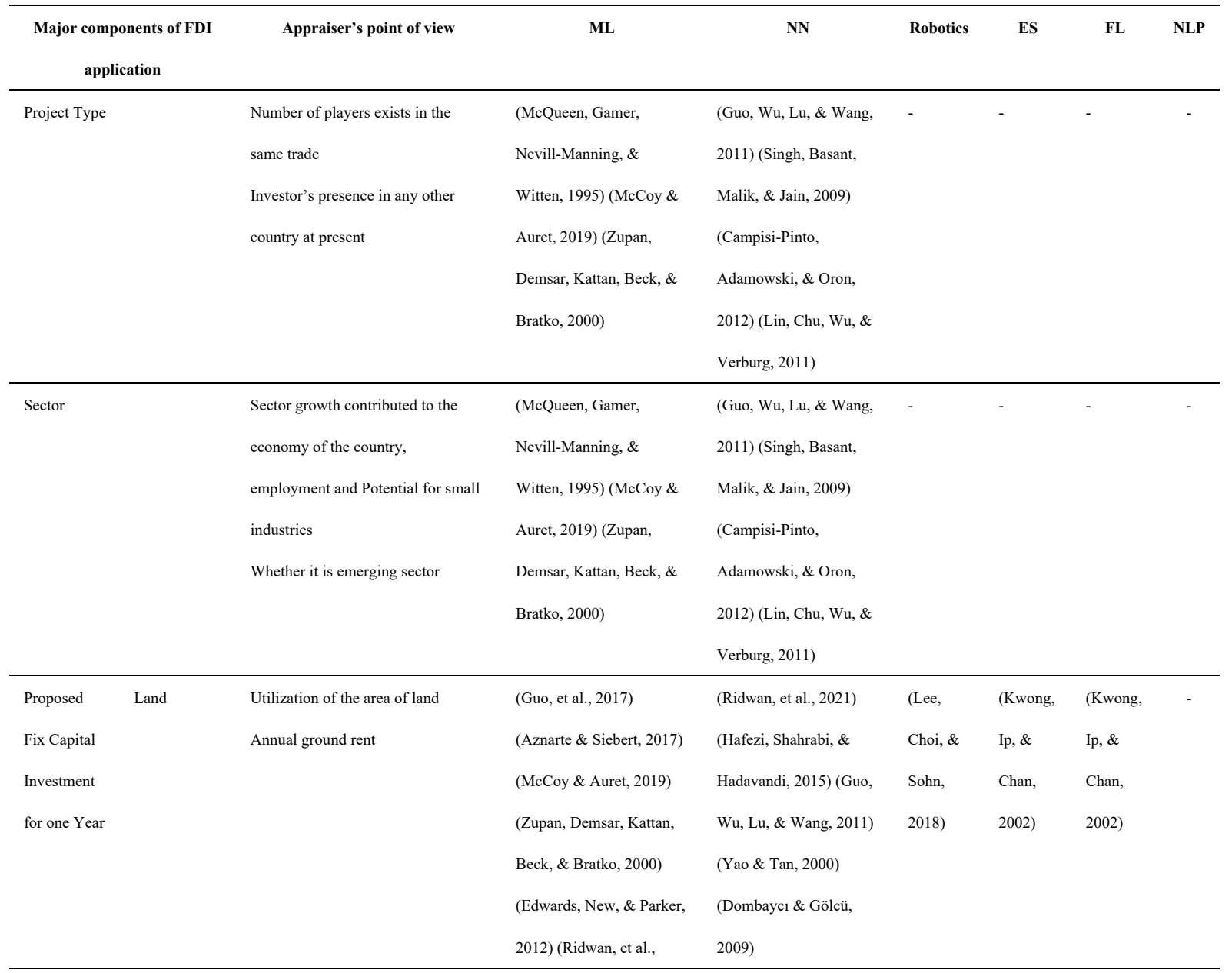




\begin{tabular}{|c|c|c|c|c|c|c|c|c|}
\hline & & & 2021) & & & & & \\
\hline & Building & Area of the building & (Guo, et al., 2017) & (Ridwan, et al., 2021) & (Lee, & (Kwong, & (Kwong, & - \\
\hline & & Commercial value of building & (Aznarte \& Siebert, 2017) & (Hafezi, Shahrabi, \& & Choi, \& & Ip, \& & Ip, \& & \\
\hline & & & (McCoy \& Auret, 2019) & Hadavandi, 2015) (Guo, & Sohn, & Chan, & Chan, & \\
\hline & & & (Zupan, Demsar, Kattan, & Wu, Lu, \& Wang, 2011) & 2018) & 2002) & 2002) & \\
\hline & & & Beck, \& Bratko, 2000) & (Yao \& Tan, 2000) & & & & \\
\hline & & & (Edwards, New, \& Parker, & (Dombayc1 \& Gölcü, & & & & \\
\hline & & & 2012) (Ridwan, et al., & 2009) & & & & \\
\hline & & & 2021) & & & & & \\
\hline & Plant \& & Local purchase value & (Guo, et al., 2017) & (Ridwan, et al., 2021) & (Lee, & (Kwong, & (Kwong, & - \\
\hline & Equipment & Import value & (Aznarte \& Siebert, 2017) & (Hafezi, Shahrabi, \& & Choi, \& & Ip, \& & Ip, \& & \\
\hline & & & (McCoy \& Auret, 2019) & Hadavandi, 2015) (Guo, & Sohn, & Chan, & Chan, & \\
\hline & & & (Zupan, Demsar, Kattan, & Wu, Lu, \& Wang, 2011) & 2018) & 2002) & 2002) & \\
\hline & & & Beck, \& Bratko, 2000) & (Yao \& Tan, 2000) & & & & \\
\hline & & & (Edwards, New, \& Parker, & (Dombayc1 \& Gölcü, & & & & \\
\hline & & & 2012) (Ridwan, et al., & 2009) & & & & \\
\hline & & & 2021) & & & & & \\
\hline Proposed V & ng capital & amount of foreign currency & (McQueen, Gamer, & (Guo, et al., 2017) & (Lee, & (Kwong, & (Kwong, & - \\
\hline Investment & ne Year & receiving & Nevill-Manning, \& & (Aznarte \& Siebert, & Choi, \& & Ip, \& & Ip, \& & \\
\hline & & Exchange rate & Witten, 1995) (Guo, et al., & 2017) (McCoy \& Auret, & Sohn, & Chan, & Chan, & \\
\hline & & & 2017) (Aznarte \& Siebert, & 2019) (Zupan, Demsar, & 2018) & 2002) & 2002) & \\
\hline & & & 2017) (McCoy \& Auret, & Kattan, Beck, \& Bratko, & & & & \\
\hline & & & 2019) (Zupan, Demsar, & 2000) (Edwards, New, \& & & & & \\
\hline & & & Kattan, Beck, \& Bratko, & Parker, 2012) (Ridwan, & & & & \\
\hline & & & 2000) (Edwards, New, \& & et al., 2021) & & & & \\
\hline & & & Parker, 2012) (Ridwan, et & & & & & \\
\hline & & & al., 2021) & & & & & \\
\hline Source of & Foreign & amount of foreign currency & (Guo, et al., 2017) & (Ridwan, et al., 2021) & (Lee, & (Kwong, & (Kwong, & - \\
\hline Finance & Share Capital & receiving as shares of common or & (Aznarte \& Siebert, 2017) & (Hafezi, Shahrabi, \& & Choi, \& & Ip, \& & Ip, \& & \\
\hline & & preferred stock & (McCoy \& Auret, 2019) & Hadavandi, 2015) (Guo, & Sohn, & Chan, & Chan, & \\
\hline & & & (Zupan, Demsar, Kattan, & Wu, Lu, \& Wang, 2011) & 2018) & 2002) & 2002) & \\
\hline & & & Beck, \& Bratko, 2000) & (Yao \& Tan, 2000) & & & & \\
\hline & & & (Edwards, New, \& Parker, & (Dombaycı \& Gölcü, & & & & \\
\hline & & & 2012) (Ridwan, et al., & 2009) & & & & \\
\hline & & & 2021) & & & & & \\
\hline & Local Share & Amount of local currency & (Guo, et al., 2017) & (Ridwan, et al., 2021) & (Lee, & (Kwong, & (Kwong, & - \\
\hline & Capital & circulation as shares of common or & (Aznarte \& Siebert, 2017) & (Hafezi, Shahrabi, \& & Choi, \& & Ip,$\&$ & Ip, \& & \\
\hline & & preferred stock & (McCoy \& Auret, 2019) & Hadavandi, 2015) (Guo, & Sohn, & Chan, & Chan, & \\
\hline & & & (Zupan, Demsar, Kattan, & Wu, Lu, \& Wang, 2011) & 2018) & 2002) & 2002) & \\
\hline & & & Beck, \& Bratko, 2000) & (Yao \& Tan, 2000) & & & & \\
\hline & & & (Edwards, New, \& Parker, & (Dombayc1 \& Gölcü, & & & & \\
\hline & & & 2012) (Ridwan, et al., & 2009) & & & & \\
\hline & & & 2021) & & & & & \\
\hline
\end{tabular}




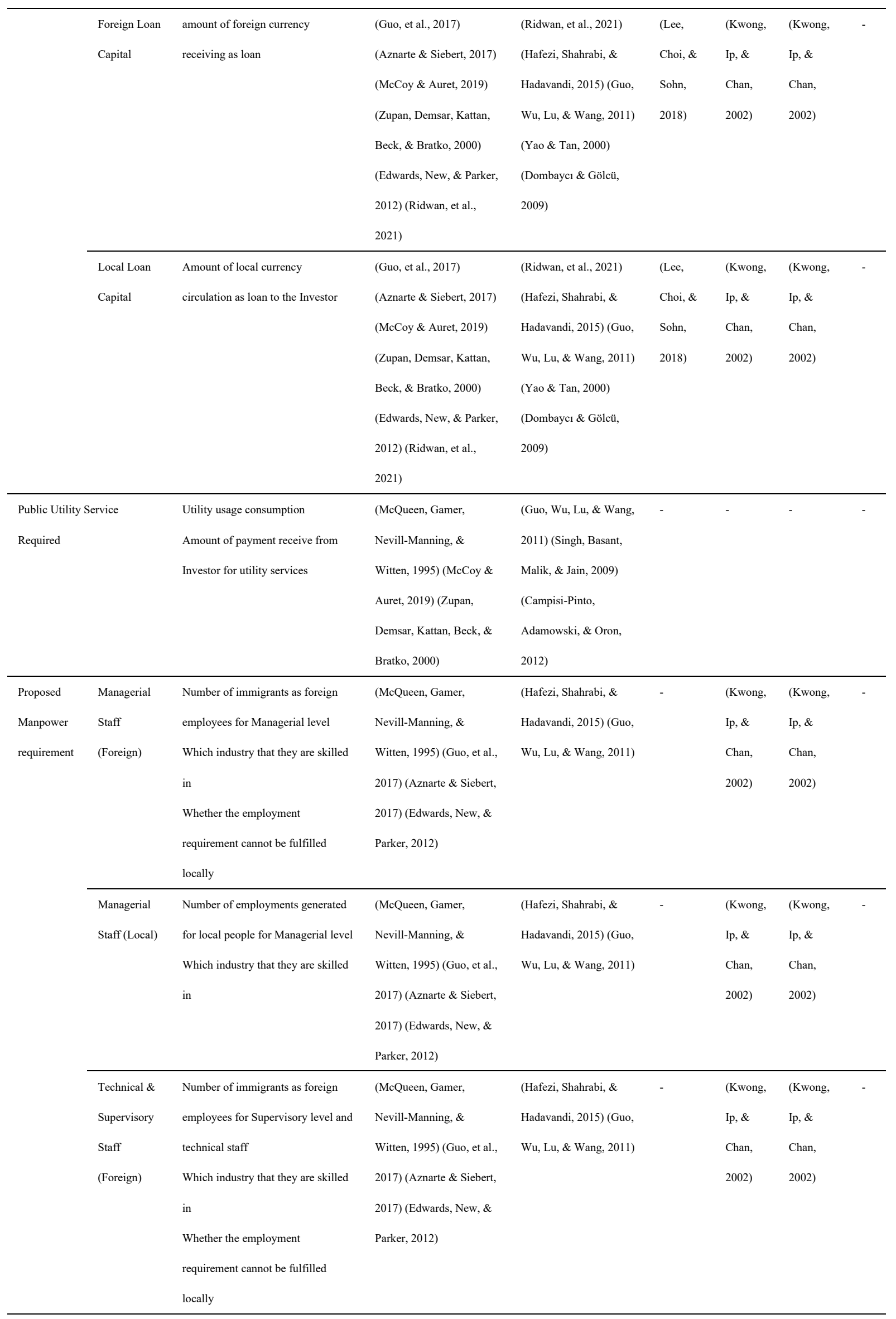




\begin{tabular}{|c|c|c|c|c|c|c|c|}
\hline Technical \& & Number of employments generated & (McQueen, Gamer, & (Hafezi, Shahrabi, \& & - & (Kwong, & (Kwong, & - \\
\hline Supervisory & for local people for Supervisory & Nevill-Manning, \& & Hadavandi, 2015) (Guo, & & Ip, \& & Ip, \& & \\
\hline \multirow[t]{4}{*}{ Staff (Local) } & level and technical staff & Witten, 1995) (Guo, et al., & Wu, Lu, \& Wang, 2011) & & Chan, & Chan, & \\
\hline & Which industry that they are skilled & 2017) (Aznarte \& Siebert, & & & 2002) & 2002) & \\
\hline & in & 2017) (Edwards, New, \& & & & & & \\
\hline & & Parker, 2012) & & & & & \\
\hline \multirow{7}{*}{$\begin{array}{l}\text { Clerical \& } \\
\text { other } \\
\text { workers } \\
\text { (Foreign) }\end{array}$} & Number of immigrants as foreign & (McQueen, Gamer, & (Hafezi, Shahrabi, \& & - & (Kwong, & (Kwong, & - \\
\hline & employees for Clerical level & Nevill-Manning, \& & Hadavandi, 2015) (Guo, & & Ip, \& & Ip, \& & \\
\hline & Which industry that they are skilled & Witten, 1995) (Guo, et al., & Wu, Lu, \& Wang, 2011) & & Chan, & Chan, & \\
\hline & in & 2017) (Aznarte \& Siebert, & & & 2002) & 2002) & \\
\hline & Whether the employment & 2017) (Edwards, New, \& & & & & & \\
\hline & requirement cannot be fulfilled & Parker, 2012) & & & & & \\
\hline & locally & & & & & & \\
\hline \multirow{6}{*}{$\begin{array}{l}\text { Clerical \& } \\
\text { other } \\
\text { workers } \\
\text { (Local) }\end{array}$} & Number of employments generated & (McQueen, Gamer, & (Hafezi, Shahrabi, \& & - & (Kwong, & (Kwong, & - \\
\hline & for local people for Clerical level & Nevill-Manning, \& & Hadavandi, 2015) (Guo, & & Ip, \& & Ip, \& & \\
\hline & Which industry that they are skilled & Witten, 1995) (Guo, et al., & Wu, Lu, \& Wang, 2011) & & Chan, & Chan, & \\
\hline & in & 2017) (Aznarte \& Siebert, & & & 2002) & 2002) & \\
\hline & & 2017) (Edwards, New, \& & & & & & \\
\hline & & Parker, 2012) & & & & & \\
\hline \multirow{9}{*}{$\begin{array}{l}\text { Skilled } \\
\text { workers } \\
\text { (Foreign) }\end{array}$} & Number of immigrants as foreign & (McQueen, Gamer, & (Hafezi, Shahrabi, \& & - & (Kwong, & (Kwong, & - \\
\hline & workers who are highly trained, & Nevill-Manning, \& & Hadavandi, 2015) (Guo, & & Ip, \& & $\mathrm{Ip}, \&$ & \\
\hline & educated, and experienced in a & Witten, 1995) (Guo, et al., & Wu, Lu, \& Wang, 2011) & & Chan, & Chan, & \\
\hline & particular job & 2017) (Aznarte \& Siebert, & & & 2002) & 2002) & \\
\hline & Which industry that they are skilled & 2017) (Edwards, New, \& & & & & & \\
\hline & in & Parker, 2012) & & & & & \\
\hline & Whether the employment & & & & & & \\
\hline & requirement cannot be fulfilled & & & & & & \\
\hline & locally & & & & & & \\
\hline \multirow{6}{*}{$\begin{array}{l}\text { Skilled } \\
\text { workers } \\
\text { (Local) }\end{array}$} & Number of employments generated & (McQueen, Gamer, & (Hafezi, Shahrabi, \& & - & (Kwong, & (Kwong, & - \\
\hline & for local workers who are highly & Nevill-Manning, \& & Hadavandi, 2015) (Guo, & & Ip, \& & Ip, \& & \\
\hline & trained, educated, and experienced & Witten, 1995) (Guo, et al., & Wu, Lu, \& Wang, 2011) & & Chan, & Chan, & \\
\hline & in a particular job & 2017) (Aznarte \& Siebert, & & & 2002) & 2002) & \\
\hline & Which industry that they are skilled & 2017) (Edwards, New, \& & & & & & \\
\hline & in & Parker, 2012) & & & & & \\
\hline \multirow{9}{*}{$\begin{array}{l}\text { Un-Skilled } \\
\text { workers } \\
\text { (Foreign) }\end{array}$} & Number of immigrants as foreign & (McQueen, Gamer, & (Hafezi, Shahrabi, \& & - & (Kwong, & (Kwong, & - \\
\hline & workers who have relatively little or & Nevill-Manning, \& & Hadavandi, 2015) (Guo, & & Ip, \& & $\mathrm{Ip}, \&$ & \\
\hline & no training or experience for a & Witten, 1995) (Guo, et al., & Wu, Lu, \& Wang, 2011) & & Chan, & Chan, & \\
\hline & specific job & 2017) (Aznarte \& Siebert, & & & 2002) & 2002) & \\
\hline & Which industry that they are skilled & 2017) (Edwards, New, \& & & & & & \\
\hline & in & Parker, 2012) & & & & & \\
\hline & Whether the employment & & & & & & \\
\hline & requirement cannot be fulfilled & & & & & & \\
\hline & locally & & & & & & \\
\hline
\end{tabular}




\begin{tabular}{|c|c|c|c|c|c|c|c|c|}
\hline & Un-Skilled & Number of employments generated & (McQueen, Gamer, & (Hafezi, Shahrabi, \& & - & (Kwong, & (Kwong, & - \\
\hline & workers & for local workers who have & Nevill-Manning, \& & Hadavandi, 2015) (Guo, & & Ip, \& & Ip, \& & \\
\hline & (Local) & relatively little or no training or & Witten, 1995) (Guo, et al., & Wu, Lu, \& Wang, 2011) & & Chan, & Chan, & \\
\hline & & experience for a specific job & 2017) (Aznarte \& Siebert, & & & 2002) & 2002) & \\
\hline & & Which industry that they are skilled & 2017) (Edwards, New, \& & & & & & \\
\hline & & in & Parker, 2012) & & & & & \\
\hline Estimated & Construction & Number of days spending for the & (McQueen, Gamer, & (Hafezi, Shahrabi, \& & - & - & - & - \\
\hline \multirow[t]{27}{*}{ time frame } & of Buildings & Construction of Buildings & Nevill-Manning, \& & Hadavandi, 2015) (Guo, & & & & \\
\hline & & Whether the requirement of & Witten, 1995) (Guo, et al., & Wu, Lu, \& Wang, 2011) & & & & \\
\hline & & constriction materials fulfilled & 2017) (Aznarte \& Siebert, & (Yao \& Tan, 2000) & & & & \\
\hline & & locally or by imports & 2017) (Lingitz, et al., & & & & & \\
\hline & & & 2018) (Edwards, New, \& & & & & & \\
\hline & & & Parker, 2012) & & & & & \\
\hline & Installation & Number of days spending for the & (McQueen, Gamer, & (Hafezi, Shahrabi, \& & - & - & - & - \\
\hline & of Machinery & Installation of Machinery & Nevill-Manning, \& & Hadavandi, 2015) (Guo, & & & & \\
\hline & & & Witten, 1995) (Guo, et al., & Wu, Lu, \& Wang, 2011) & & & & \\
\hline & & & 2017) (Aznarte \& Siebert, & (Yao \& Tan, 2000) & & & & \\
\hline & & & 2017) (Lingitz, et al., & & & & & \\
\hline & & & 2018) (Edwards, New, \& & & & & & \\
\hline & & & Parker, 2012) & & & & & \\
\hline & Trial & Number of days spending for & (McQueen, Gamer, & (Hafezi, Shahrabi, \& & - & - & - & - \\
\hline & Production & Production trial & Nevill-Manning, \& & Hadavandi, 2015) (Guo, & & & & \\
\hline & & & Witten, 1995) (Guo, et al., & Wu, Lu, \& Wang, 2011) & & & & \\
\hline & & & 2017) (Aznarte \& Siebert, & (Yao \& Tan, 2000) & & & & \\
\hline & & & 2017) (Lingitz, et al., & & & & & \\
\hline & & & 2018) (Edwards, New, \& & & & & & \\
\hline & & & Parker, 2012) & & & & & \\
\hline & Start & Number of days spending for the & (McQueen, Gamer, & (Hafezi, Shahrabi, \& & - & - & - & - \\
\hline & Commercial & whole implementation process till & Nevill-Manning, \& & Hadavandi, 2015) (Guo, & & & & \\
\hline & Production or & starting the commercial operation & Witten, 1995) (Guo, et al., & Wu, Lu, \& Wang, 2011) & & & & \\
\hline & Operation & & 2017) (Aznarte \& Siebert, & (Yao \& Tan, 2000) & & & & \\
\hline & & & 2017) (Lingitz, et al., & & & & & \\
\hline & & & 2018) (Edwards, New, \& & & & & & \\
\hline & & & Parker, 2012) & & & & & \\
\hline Estimated & Quantity of & The revenue generating to the & (Guo, et al., 2017) & (Hafezi, Shahrabi, \& & (Lee, & (Kwong, & (Kwong, & - \\
\hline Production & exports & country from exports & (Aznarte \& Siebert, 2017) & Hadavandi, 2015) (Guo, & Choi, \& & $\mathrm{Ip}, \&$ & Ip, \& & \\
\hline or Services & & Cost of imports for raw materials & (Edwards, New, \& Parker, & Wu, Lu, \& Wang, 2011) & Sohn, & Chan, & Chan, & \\
\hline \multirow[t]{6}{*}{ for one year } & & & 2012) & (Dombayc1 \& Gölcü, & 2018) & 2002) & 2002) & \\
\hline & & & & 2009) (Chang, Liu, \& & & & & \\
\hline & & & & Fan, 2009) (Campisi- & & & & \\
\hline & & & & Pinto, Adamowski, \& & & & & \\
\hline & & & & Oron, 2012) & & & & \\
\hline & Quantity of & Quantity of final products selling & (Guo, et al., 2017) & (Hafezi, Shahrabi, \& & (Lee, & (Kwong, & (Kwong, & 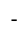 \\
\hline
\end{tabular}




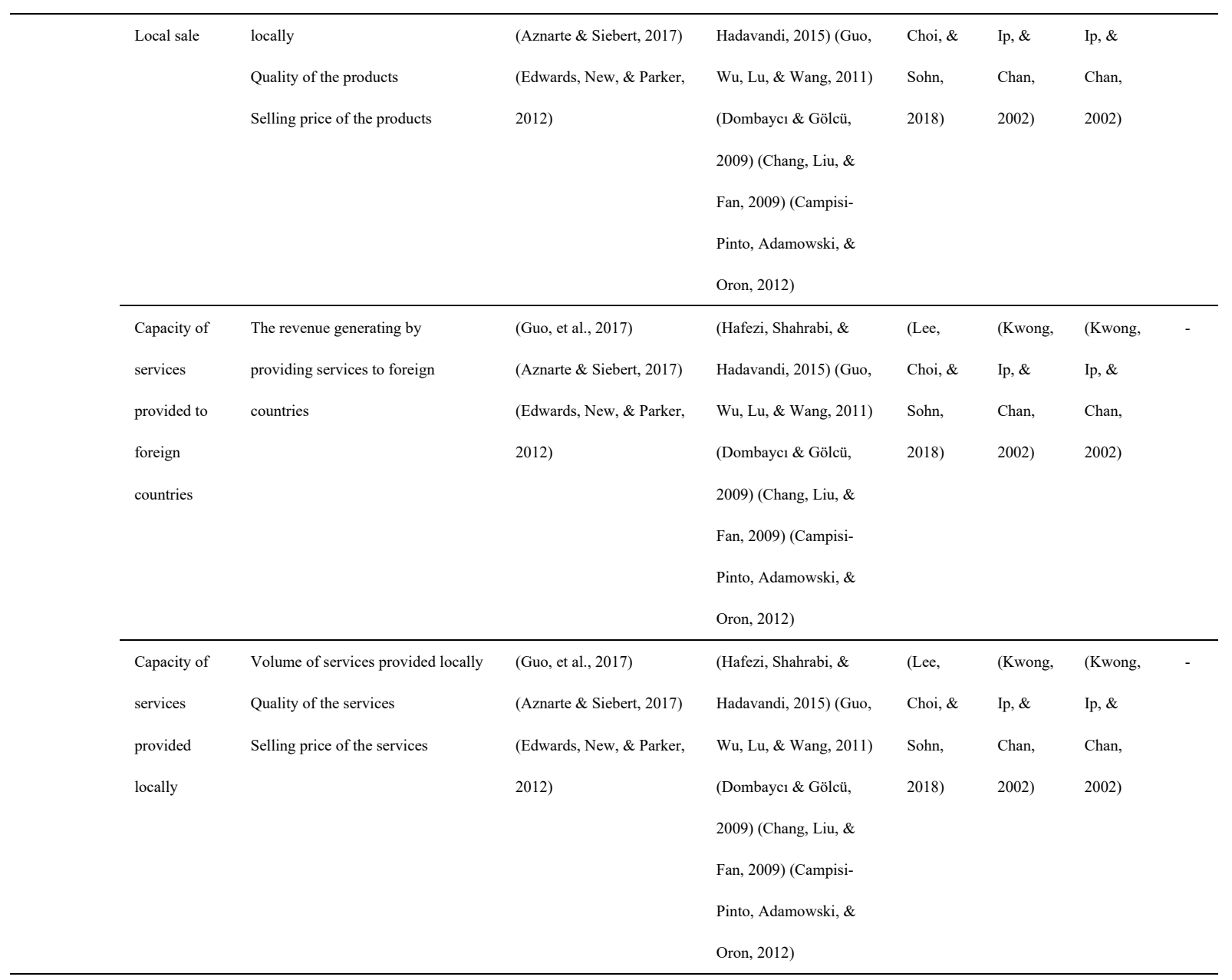

According to the representation of table 2 Machine Learning and Neural Network are both most suitable branches to automate the FDI application evaluation. However, Robotics, Expert Systems, Fuzzy Logic and Natural Language Processing are widely used in other purposes than evaluating something in different aspects and come for a conclusion. As extracted the major components of FDI application in this research, the major components in agriculture were taken as the parameters to apply the ML to diagnose the brown spots in agriculture. All the component in agriculture is based on quality, time and amount. Conditions of seed, Conditions of fruit pods, Conditions of leaves, Conditions of stem, Conditions of roots are mostly quality based. However, the time of occurrence, cropping history and temperature changes during the time are time-based compotes. The temperature, number of seeds and size of leaves number of fruits are the quantity-based components.

Like the brown spot disease in agriculture, the ML has used to diagnose the spread of dengue different areas of a country. Although it uses different algorithms for the forecast, the nature of input components are similar. The presence of Aedes mosquitoes, dengue of the virus, urbanization of areas are the components based on quality. Duration of monsoon climate, life of a mosquitoes, transmission of mosquitoes and transmission of dengue virus are the time-based components. Mosquito vector density, number of dengue-control programs and number of highly urbanized environment in the country are amount based input component to the dengue forecast model.

The BNNMAS uses the algorithms of NN always use the number-based inputs to the model. The stock price prediction is totally depending on the stock values fluctuation during a specific time frame for a company. As a result of the process, it forests the stock princes and price patters in future. Therefore, this process has major similarities to forecast the financial benefits by analyzing a FDI application. The forecasting of foreign exchange rates by using $\mathrm{NN}$ takes the time series data and technical indicators, such as moving average, are fed to neural networks to capture the underlying rules of the movement in currency exchange rates. The inputs and outputs when use of $\mathrm{NN}$ to forecast the future sales of a printed circuit board is also has similar features as two of the above. Therefore, these three models and be easily customized to evaluate the time-based and amount- based components of FDI application. The wind speed forecast, ambient temperature forecast, and river water quality predict has 
quality, time and amounts-based input measures. However, the result will be amount based in most of the models and these models can be easily customized to evaluate the quantity-based components of FDI application.

\section{Conclusions}

Artificial intelligence is the subject of much debate in today's world and has caused much confusion. Specific applications of AI include Machine Learning, Neural Network, Robotics, Expert Systems, Fuzzy Logic and Natural Language Processing. Each of these branches has different algorithms and each algorithm specialized to perform specific actions. This research analyses the application of the branchers of AI in the scenarios similar to FDI application evaluation. The components of AI application can be evaluated based on the quality of the information, duration of the process and quantity. The most suitable algorithms to evaluate each component of the FDI application was determined based on the application of algorithms in the literature. As a result of the analysis ML and NN algorithms were mainly used to forecast the quality wise, and quantity wise future predictions based on the past data. The developed ML and NN models trained by quality based, time based, and quantity-based input data were provided accurate forecasted results. The decision of approval for a FDI project is based on the potential value to the country's economy that can be predicted when the project is commercially operated. Therefore, a dedicated model developed by ML, NN or combination of both can be recommend evaluating the FDI application form.

\section{References}

Aznarte, J. L., \& Siebert, N. (2017). Dynamic Line Rating Using Numerical Weather Predictions and Machine Learning: A Case Study. IEEE Transactions on Power Delivery, 32(1), 335 - 343. https://doi.org/10.1109/TPWRD.2016.2543818

Bangladesh Investment Development Authority. (2021, Novemeber 20). Bangladesh Investment Development Authority. $\quad$ Retrieved Novemeber $\quad 20, \quad 2021, \quad$ from https://fid.portal.gov.bd/sites/default/files/files/fid.portal.gov.bd/forms/87c6a6ad_1092_4417_a6dd_df7980 $85 \mathrm{~d} 1$ ce/registration-of-industrial-invesment-project-1.pdf

Board of Investment of Pakistan. (2021, November 20). Board of Investment of Pakistan. Retrieved November 20, 2021, from https://invest.gov.pk/sites/default/files/inline-files/Investment\%20Guide\%20.pdf

Board of investment of Sri Lanka. (2021, November 20). Board of investment of Sri Lanka. Retrieved November 20, 2021, from https://investsrilanka.com/wp-content/uploads/2020/04/Section-17.pdf

business-standard. (2021). What is Foreign Direct Investment(FDI). (www.business-standard.com/) Retrieved 10 02, 2021, from https://www.business-standard.com/about/what-is-fdi

Campisi-Pinto, S., Adamowski, J., \& Oron, G. (2012). Forecasting UrbanWater Demand ViaWavelet-Denoising and Neural Network Models. Case Study: City of Syracuse, Italy. Water Resour Manage, 26(1), 3539-3558. https://doi.org/10.1007/s11269-012-0089-y

CCG. (2021, 09 28). Market Overview. (International Trade Administration) Retrieved November 1, 2021, from https://www.trade.gov/country-commercial-guides/sri-lanka-market-overview

Chang, P. C., Liu, C.-H., \& Fan, C. Y. (2009). Data clustering and fuzzy neural network for sales forecasting: A case study in printed circuit board industry. Knowledge-Based Systems, 22(1), 344-355. https://doi.org/10.1016/j.knosys.2009.02.005

Chopra, A., Prashar, A., \& Sain, C. (2013). Natural Language Processing. International Journal of Technology Enhancements and Emerging Engineering Research, 1(4), 131-134.

Chui, M., Henke, N., \& Miremad, M. (2018, 07 20). Most of AI’s Business Uses Will Be in Two Areas. (Harvard Business Review) Retrieved November 12, 2021, from https://hbr.org/2018/07/most-of-ais-business-useswill-be-in-two-areas

Dombayc1, Ö. A., \& Gölcü, M. (2009). Daily means ambient temperature prediction using artificial neural network method: A case study of Turkey. Renewable Energy, 34(1), $1158-1161$. https://doi.org/10.1016/j.renene.2008.07.007

Edirisinghe, H., \& Koggalage, D. (2021). The Role of Entrepreneurs in Business Development. International Journal of Scientific \& Engineering Research, 12(5), 768-774.

Edirisinghe, L. (2017). Strategic Marketing Management in Container Shipping: application of Ten S Model. CINEC Acadamic Journal, 2(2017 in Press), 96-104. https://doi.org/10.4038/caj.v2i0.63

Edirisinghe, L. (2017). The Influence of Logistics Competence in International Trade in Sri Lanka: A 
Contemporary Study. 6th International Conference of Sri Lanka Forum of University Economists (pp. 53-59). Mihintale: Rajarata University of Sri Lanka. https://doi.org/10.2139/ssrn.3305996

Edwards, R. E., New, J., \& Parker, L. E. (2012). Predicting future hourly residential electrical consumption: A machine learning case study. Energy and Buildings, 49(1), 591-603. https://doi.org/10.1016/j.enbuild.2012.03.010

Guo, P., Liu, T., Zhang, Q., Wang, L., Xiao, J., Zhang, Q., . . Ma, W. (2017). Developing a dengue forecast model using machine learning: A case study in China. PLOS Neglected Tropical Diseases, 11(10), 1 - 22. https://doi.org/10.1371/journal.pntd.0005973

Guo, Z. H., Wu, J., Lu, H. Y., \& Wang, J. Z. (2011). A case study on a hybrid wind speed forecasting method using BP neural network. Knowledge-Based Systems, 24(1), 1048-1056. https://doi.org/10.1016/j.knosys.2011.04.019

Hafezi, R., Shahrabi, J., \& Hadavandi, E. (2015). A Bat-Neural Network Multi-Agent System (BNNMAS) For Stock Price Prediction: Case Study of DAX Stock Price. Applied Soft Computing, 29(1), 196-210. https://doi.org/10.1016/j.asoc.2014.12.028

IBM. (2020, 07 15). Machine Learning. (www.ibm.com) Retrieved October 1, 2021, from https://www.ibm.com/cloud/learn/machine-learning

Invest Maldives. (2021, November 20). Invest Maldives. Retrieved November 20, 2021, from https://business.egov.mv/Downloads/Forms/Foreign_Investment_Application_Form.pdf

Kok, J. N., Boers, E. J., Kosters, W. A., Putten, P. V., \& Poel, M. (2020). Artificial Intelligence: Definition, Trends, Techniques, and Cases. Paris: Encyclopedia of Life Support Systems. Retrieved from http://www.eolss.net/sample-chapters/c15/e6-44.pdf

Kwong, C. K., Ip, W. H., \& Chan, J. W. (2002). Combining scoring method and fuzzy expert systems approach to supplier assessment: a case study. Integrated Manufacturing Systems, 13(7), 512 - 519. https://doi.org/10.1108/09576060210442671

Lee, W. S., Choi, H. S., \& Sohn, S. Y. (2018). Forecasting new product diffusion using both patent citation and web search traffic. Plos One, 13(4), 1-12. https://doi.org/10.1371/journal.pone.0194723

Lin, Y. P., Chu, H. J., Wu, C. F., \& Verburg, P. H. (2011). Predictive ability of logistic regression, auto-logistic regression and neural network models in empirical land-use change modeling - a case study. International Journal of Geographical Information Science, 25(1), 65-87. https://doi.org/10.1080/13658811003752332

Lingitz, L., Gallina, V., Ansari, F., Gyulai, D., Pfeiffer, A., Sihn, W., \& Monostori, L. (2018). Lead time prediction using machine learning algorithms: A case study by a semiconductor manufacturer. 51st CIRP Conference on Manufacturing Systems, 72, 1051-1056. Stockholm. https://doi.org/10.1016/j.procir.2018.03.148

McCoy, J. T., \& Auret, L. (2019). Machine learning applications in minerals processing: A review. Minerals Engineering, 132(1), 95-109. https://doi.org/10.1016/j.mineng.2018.12.004

McQueen, R. J., Gamer, S. R., Nevill-Manning, C. G., \& Witten, I. H. (1995). Applying machine learning to agricultural data. Computers and Electronics in Agriculture, 1(12), 275-293. https://doi.org/10.1016/01681699(95)98601-9

Moran, T., Görg, H., Seric, A., \& Krieger, Boden, C. (2017, 10 19). Attracting quality foreign direct investment in developing countries. (International Growth Centre) Retrieved October 5, 2021, from https://www.theigc.org/blog/attracting-quality-foreign-direct-investment-developing-countries/

Nadkarni, P. M., Ohno-Machado, L., \& Chapman, W. W. (2011). Natural language processing: an introduction. Journal of the American Medical Informatics Association, 18(5), 544-551. https://doi.org/10.1136/amiajnl2011-000464

Nwanji, T. I., Howell, K. E., Faye, S., Otekunrin, A. O., Eluyela, D. F., Lawal, A. I., \& Eze, S. C. (2020). Impact of Foreign Direct Investment on the Financial Performance of Listed Deposit Banks in Nigeria. International Journal of Financial Research, 11(2), 323-347. https://doi.org/10.5430/ijfr.v11n2p323

OECD. (2002). Foreign Direct Investment for Development. France: Organisation for Economic Co-operation and Development. https://doi.org/10.1787/9789264199286-en

O'Leary, D. E. (2013). Artificial Intelligence and Big Data. IEEE Intelligent Systems, 28(2), 96-99. https://doi.org/10.1109/MIS.2013.39 
Ridwan, W. M., Sapitang, M., Aziz, A., Kushiar, K. F., Ahmed, A. N., \& El-Shafie, A. (2021). Rainfall forecasting model using machine learning methods: Case study Terengganu, Malaysia. Ain Shams Engineering Journal, 12(2), 1651-1663. https://doi.org/10.1016/j.asej.2020.09.011

Saeed, K., \& Lamech, R. (2003). What International Investors Look For When Investing In Developing Countries. Washington, DC: World Bank.

Schwab, K. (2019). Global Competitiveness Report. Geneva: World Economic Forum.

Singh, K. P., Basant, A., Malik, A., \& Jain, G. (2009). Artificial neural network modeling of the river water $\begin{array}{lllll}\text { quality-A } & \text { case } & \text { study. } & \text { Ecological } & \text { Modelling, }\end{array}$ https://doi.org/10.1016/j.ecolmodel.2009.01.004

UNCTAD. (2003). Foreign Direct Investment and Performance Requirements: New Evidence from Selected Countries. (https://unctad.org/system/) Retrieved November 10, 2021, from https://unctad.org/system/files/official-document/iteiia20037_en.pdf

UNCTAD. (2004). Investment Policy Review -Sri Lanka. Geneva: United Nations Conference on Trade and Development.

UNCTAD. (2009). UNCTAD Training Manual on Statistics for FDI and the Operations of TNCs. (https://unctad.org) Retrieved November 11, 2021, from https:/unctad.org/system/files/officialdocument/diaeia20091_en.pdf

Yao, J., \& Tan, C. L. (2000). A case study on using neural networks to perform technical forecasting of forex. Neurocomputing, 34(1), 2000. https://doi.org/10.1016/S0925-2312(00)00300-3

Zupan, B., Demsar, J., Kattan, M. W., Beck, J. R., \& Bratko, I. (2000). Machine learning for survival analysis: a case study on recurrence of prostate cancer. Artificial Intelligence in Medicine, 20(1), 59-75. https://doi.org/10.1016/S0933-3657(00)00053-1

\section{Copyrights}

Copyright for this article is retained by the author(s), with first publication rights granted to the journal.

This is an open-access article distributed under the terms and conditions of the Creative Commons Attribution license (http://creativecommons.org/licenses/by/4.0/). 